\title{
The Sixth Congress of Russian Physicists.
}

THE Russian Physical Society usually meets in one of the larger university towns, but this year a new departure was made, and in order to visit some of the more remote universities the congress became itinerant, in much the same way as is done by the British Association when it visits the Dominions. A number of foreign physicists were invited to become the guests of the society, and those who were fortunate enough to be able to do so were treated with the most generous hospitality. We have undoubtedly had as interesting a journey as we are ever likely to make.

The meeting began on Aug. 5 in Moscow under the presidency of Prof. Ioffe, of Leningrad. Here most of the papers were read, but there was no time for the Russian papers to be translated, and so those of the visitors who could not understand the language had plenty of opportunity for seeing the sights. Apart from the monuments and museums, we were shown a number of scientific institutions, among them the Biophysical Institute of Prof. Lazarev, where experiments over a most unusually wide field are being carried on. From Moscow we went to Nijni-Novgorod, where the great fair was in progress, though rather fallen from its former importance, and after a day there, including a meeting at the University, we took ship on the Volga. A special boat had been chartered, and this provided a great opportunity for the informal discussion of physical questions. It also made it possible to stop at any places of interest on the river, or when the weather turned hot to see the beautiful sight of two hundred physicists simultaneously enjoying a bathe.

We were most hospitably entertained by the University at Kazan, a beautiful city and the capital of the Tartar Republic, and we shall always think of Kazan as the culminating point of the whole tour. From there we moved on to Saratov, where the closing session was held on Aug. 15. Though this was the formal end of the congress, a continuation had been arranged in which many of the Russians and nearly all the visitors took part. We went on down the
Volga to Stalingrad (formerly Tsaritsin) and then took train across the steppes to the Caucasus. From Vladikavkas we were carried in motors over the wonderful Georgian Road to Tiflis, where we were again entertained by the University. There the party broke up, most returning by various ways to Moscow, but a few of us found a ship going from Batum to Constantinople, and so returned by the Mediterranean.

For one who knows no Russian it is not possible to give a detailed account of the subjects of the papers, but physies certainly appear to be in a flourishing condition in Russia. Perhaps the most interesting work is that of Prof. Ioffe on the reflection of electrons -including an unsuccessful attempt to detect polarisation-and that of Profs. Mandelstamm and Landsberger. The latter described how they had independently discovered Raman's phenomenon, the scattering of light with changed frequency. This was predicted some years ago by the dispersion theory of Kramers (and still earlier by Smekal), and the verification is made by scattering the light from a solid or liquid and observing the change of frequency. This change is a measure of the wave-lengths of the infrared absorption of the scattering material, and so, apart from its direct interest, the phenomenon promises to be important for the spectroscopy of solids. In addition to the Russian papers, lectures were given by the visitors on various subjects; among them may be mentioned Prof. Ladenburg's verification of the 'negative dispersion,' also predicted by Kramers (see Nature, Sept. 22, p. 438).

The general condition of Russian scientific workers seems to be more favourable than it was reported to be a few years ago. Their labours are very directly encouraged under the present regime, and, apart from the general impoverishment of the country, their chief hardship appears to be a sense of isolation due to the great difficulty they have in visiting other countries. Their guests will certainly all try to mitigate this difficulty in return for such a delightful tour.

\section{Research in Aeronautics. ${ }^{1}$}

THE keynote of the policy of the Aeronautical Research Committee during the year 1927-28 appears to have been a recognition of the importance of close co-operation with the aircraft industry and the Services on one hand, coupled, on the other hand, with a consistently scientific attitude to test and research in the problems associated with these two branches. The numerous advances recorded and the high quality of the experimental work are a full justification of this policy.

The general progress in Great Britain resulting from research is exemplified in the performance of the British seaplanes competing for the Schneider Trophy. The immediate results are of course attributable to the designers of the machines and engineers, and to the splendid piloting by the R.A.F. officers, but a great deal of preliminary ground work was covered by close co-operation between the individual designers and the trained research staff at the National Physical Laboratory. Several models of each racing type were tested in the duplex tunnel at the N.P.L. in the endeavour to obtain results at the highest possible Reynolds' number, that is, as close to full scale con-

${ }_{2}$ Aeronautical Research Committee. Report for the Year 1927-28. Pp. 63. (London: H.M. Stationery Office, 1928.) 2s. net. ditions as possible, and the conclusions arrived at, after consultations between the designers and the N.P.L. staff, led to definite improvements. The Committee quite rightly stresses the importance of close co. operation between the designer and the actual research worker, as a vital factor in progress of this nature.

The part played by joint action of a similar kind is exemplified by the development of mechanisms for avoidance of control failure during stalling. The Committee has now spent some considerable time in a close study of the forces operating during the stall, and of the actual motion of the aeroplane in that condition, in the hope of preventing the serious type of accident which frequently follows an inadvertent stall. This hope has been fulfilled, and out of the original slot system there have developed several methods for reducing this danger. In particular, the use of a slot which automatically closes at low wing incidences, and so avoids the loss of performance due to an open slot, has greatly assisted this development. Meanwhile, various methods of using slots at the wing tips are being extensively tried in the Services and upon civil aeroplanes.

Valuable work is also recorded on the problem of wing flutter; the aerodynamic and structural factors 
that originate it have been analysed, and studied experimentally on models, while modifications in design have been suggested with the view of its reduction, if not actual elimination.

So far as the power unit is concerned, the Committee records many important advances. Distinct progress has been made in the determination of the torsional vibrations of crank shafts in a form suitable for design routine, and there is a first indication that a critical speed lower than the normal running speed may safely be allowed. The question of compressionignition engines has been examined. The advantages offered by an engine of this type are substantial : they include such features as the diminution of fire risk by use of a fuel of high flash-point; a fuel consumption possibly lower than that of a petrol engine ; a cheap fuel ; and a diminution of the heat that must be dissipated by the cooling system. On the other hand, there is the disadvantage of high maximum pressure and a greater weight per engine h.p. Starting difficulties are also experienced, but it is anticipated that these may be overcome.

Close co-operation with the Services is evidenced by the fact that measurements are being made of the fuel consumption in Service squadrons, and these indicate very wide variation as between one engine and another in the same flight.

Pure aerodynamic research also finds its place. Problems of fluid motion have been attacked both theoretically and by experiment. In particular, a detailed experimental analysis of the state of eddying flow being a two-dimensional body has been carried through, the results being in general agreement with Kàrmàn's theory of vortex streets. Thus, step by step, closer insight is being afforded into the complicated state of turbulence in the wake of a moving body, and the part this plays in relation to the aerodynamic forces that arise. It is clear that an important de- sideratum for the future study of air-flow problems is the construction of an instrument capable of following and recording the rapid velocity fluctuations in an airstream. Up to the present, it is only at low frequencies of about four per second that the wave form can be accurately determined, although the actual frequency can be measured up to eighty per second.

Year after year has witnessed the evolution of a special aerodynamic technique both experimentally and instrumentally. This year yet another step is to be taken which may have the effect still further of replacing full scale experiments by those on models. A compressed-air tunnel is under erection at the N.P.L. and a high-speed tank at the Royal Aircraft Establishment. The new air tunnel will be approximately $17 \mathrm{ft}$. in diameter and $50 \mathrm{ft}$. long, and a pressure of 22 atmospheres will be attained. This will enable a large amount of experimental work to be done under controlled conditions in the laboratory, which otherwise could only be conducted much more slowly and at a greater cost in free flight. Ample facilities must, nevertheless, remain for full scale experiments, as an ultimate standard of reference. In the new highspeed tank, models of seaplane bodies and floats will be tested at speeds up to $40 \mathrm{ft}$. $/ \mathrm{sec}$.

It is impossible in such a brief notice to do justice to the manifold activities of the panels of the Aeronautical Research Committee or of the numerous individual workers associated with them. The mere titles of the sub-committees speak for themselves: accidents, aerodynamics, air transport, alloys, compressed-air tunnel, design, elasticity and fatigue, engine, flutter, interference, relations with industry, seaplane, symbols, wind structure. The scientific problems that arise are of no mean order. The success recorded in this report is in no small measure due to the effectiveness with which the scientific work has been co-ordinated in the administration.

\section{The British Industries Fair.}

$\mathrm{T}$ HE next British Industries Fair, organised by the Department of Overseas Trade, is to be held at the White City, Shepherd's Bush, on Feb. 18-Mar. 1, 1929. The Government has again made a grant of $£ 25,000$ for the purpose of advertising the fair. The fair is to be restricted to trade buyers from 10 A.M. to 4 P.M. each day, but to enable the general public to see this thoroughly representative display of products of the home country and the Empire overseas, they will be admitted daily from 4 P.M. to 8 P.M.

The number of exhibitors increased from 914 in 1927 to 1223 in 1928, and the increase in the home buyers visiting the fair was 40 per cent in 1928, and the increase in foreign buyers 24 per cent. Moreover, the attendance of the general public showed an increase of 15 per cent. It is hoped, and indeed expected, that the fair of 1929 will show a marked increase on these figures, and, to meet this growth, the total area available will be increased from 257,000 square feet in 1928 to 400,000 square feet in 1929 .

The scientific instrument section of the British Industries Fair was formed as a separate section in 1926, when about 18 firms exhibited, occupying 750 square feet. Last year these numbers had grown respectively to 52 firms and a space of 6000 square feet. For 1929 applications have already been received from 45 firms for a space of approximately 5600 square feet, without taking into account about 2000 feet reserved for the British Photographic Association.
It is to be hoped that the various branches of the British Scientific Instrument Industry-optical, electrical, mechanical, and other-will not neglect the opportunity thus provided of bringing to the eyes, not only of home and foreign trade buyers, but also of the general public, a representative display of British products in these fields. Only goods manufactured within the British Empire may be shown, and then only by the actual manufacturers or by firms who control the complete output.

There have been marked advances in the design, quality, and performance of British scientific instruments, as well as of the production of optical glass, in Great Britain in recent years, and the British Industries Fair affords not only a useful, but also an almost indispensable, means of bringing vividly before potential buyers and users the nature and the extent of the progress that has been made.

The British scientific instrument industry has undoubtedly been hampered in the development of certain of its specialised products, by a current legend or prejudice, for some classes, in favour of the products of this or of that foreign country. Even where such a prejudice may have been based originally upon a superiority in fact, it tends to live on and to influence purchase long after it has ceased to be true, and the British manufacturer thus gets less than the credit due to him for the improved quality and performance of his productions. The Fair is one way, and an excellent way, to remove or to lessen the handicap which British manufacturers suffer.

No. 3077 , VoL. 122] 